\title{
Sporcularda ayak bileği dış yan bağ yaralanmalarında güncel yaklaşımlar
}

\section{Current concepts in the management of ankle lateral ligament instability in athletes}

\author{
Kaan Irgit, Mert Topkar \\ Marmara Üniversitesi Tıp Fakültesi, Ortopedi ve Travmatoloji Anabilim Dalı, İstanbul
}

\begin{abstract}
Ayak bileği burkulması, ortopedi ve travmatoloji pratiğinde en sık görülen yaralanmadır ve olguların yaklaşık \%85'i dış yan bağ kompleksini ilgilendirir. Yaralanma bu kadar sık görülse de her hastada kronik ayak bileği instabilitesi gelişmez. Çoğu yaralanma plantar fleksiyondaki ayağa uygulanan bir inversiyon zorlaması ile meydana gelir. Dış yan bağ kompleksi anterior talofibular bağ (ATFL), kalkaneofibular bağ (CFL) ve posterior talofibular bağdan (PTFL) meydana gelir. Mekanik instabilite, bağlardaki yırtığa bağlı oluşur. Fonksiyonel instabilite ise ayak bileği burkulması sonrası gelişen propriyoseptif ve kas defisitine bağlı gelişir. Altı aydan uzun süren instabilite durumuna kronik instabilite denir. Uygun konservatif tedaviye rağmen bulguları devam eden hastalarda ayak bileği stabilitesini sağlamak için cerrahi tedavi gereklidir. Cerrahiler; anatomik direkt tamir, non anatomik bağ rekonstrüksiyonu veya artroskopik tedavi olarak ayrılabilir. Anatomik tamirler günümüzde daha çok tercih edilen cerrahi tekniktir. Son zamanlarda anatomik tamir destek fiber sütürlerle yapılmaya başlanmış ve bu, rehabilitasyonun hızlanmasını sağlamıştır. Artroskopik anatomik tamir bir diğer güncel tedavi seçeneğidir ve gittikçe yaygınlaşmaktadır. Açık veya kapalı anatomik tamir sonrası eski seviye spora dönüş \%86 civarındadır. Bu derlemenin amacı, son yıllarda ayak bileği dış yan bağ yaralanmaları sonrası spora dönüş ile ilgili yeni çıkan önerileri, kronik ve akut gevşeklikte kullanılan yeni cerrahi teknikleri ve sporculardaki akut bağ yaralanmasına yaklaşımdaki yeni yöntemleri gözden geçirmektir.
\end{abstract}

Anahtar sözcükler: ayak bileği burkulması; kronik instabilite; Broström; internal brace; artroskopi; anatomic tamir

\begin{abstract}
Ankle sprain is the most common athletic injury regarding musculoskeletal system and $85 \%$ is related with lateral ligament disruption. Despite the high incidence chronic instability is not encountered in most of the cases. Inversion injury on plantar flexed ankle is the most common injury mechanism. Lateral ankle ligament complex comprises of ATFL, CFL and PTFL. Mechanical instability is due to the disruption of the ligaments. However, functional instability is mainly due to the loss of proprioception and muscle deficit. Instability that lasts longer than 6 months is considered as chronic. Despite the appropriate rehabilitation programs instability may develop and requires surgical management. Surgical options are anatomic direct repair, non-anatomic ligament reconstruction and arthroscopic interventions. Recently, ligament augmentation with fibertape is promoted for enhancing the ligament which has reduced the duration of rehabilitation. Arthroscopic anatomic repair is another current treatment option, and is becoming increasingly common. Return to sports is about $86 \%$ after open or arthroscopic techniques. The purpose of this paper is to review the current techniques and the latest recommendations about return to sports that are used in acute and chronic ankle instability in athletes.
\end{abstract}

Key words: ankle sprain; chronic instability; Broström; internal brace; arthroscopy; anatomic repair

talofibular bağdan (PTFL) meydana gelir. ATFL ve CFL ana statik bağ yapılarıdır. CFL ekstrakapsüler kordon şeklinde hem tibiotalar hem de talokalkaneal eklemi stabilize eder. PTFL en kuvvetli bağ yapısıdır. ATFL, plantar fleksiyondaki ayağın inversiyon zorlamasına karşı ana engeldir. Mekanik instabilite olan hastalarda ATFL tek başına veya CFL ile birlikte yaralanmıştır.

- İletişim adresi: Doç. Dr. Kaan Irgıt, Marmara Üniversitesi Tıp Fakültesi, Ortopedi ve Travmatoloji Anabilim Dalı, İstanbul Tel: 0216 - 6254545 e-posta: kaanirgit@yahoo.com

- Geliș tarihi: 1 Ocak $2018 \quad$ Kabul tarihi: 1 Ocak 2018 
1965 yılında Freeman, ayak bileğinde burkulma sonrası devam eden belirtilerin nedeninin ayak bileği eklemindeki mekanoreseptörler olduğu hipotezini ortaya atmıştır. ${ }^{[2]}$ Altı aydan uzun süren instabilite durumuna kronik instabilite denir. En az bir kez burkulma geçiren kişiler, eğer uygun tedavi almazlar ise kronik ayak bileği instabilitesi geliştirmeye daha yatkın olurlar. ${ }^{[3]}$ Kronik instabilite gelişme riski, tek bir ciddi burkulma sonrası, birkaç basit burkulmaya göre daha fazladır. Burkulma yaşayan hastaların \%55'inin herhangi bir tedavi almadığı da yapılan çalışmalarda gösterilmiştir. ${ }^{[4]}$

Yaralanma bu kadar sık görülse de her hastada kronik ayak bileği instabilitesi gelişmez. Mekanik instabilite gelişen hastalarda tibiotalar eklemde patolojik hipermobilite gözlemlenirken, fonksiyonel instabilite gelişen hastalarda daha subjektif şikayetler meydana gelir; ancak radyolojik instabilite bulguları olmaz. Mekanik instabilite bağlardaki yırtığa bağlı oluşur. Fonksiyonel instabilite ise ayak bileği burkulması sonrası gelişen propriyoseptif ve kas defisitine bağlı gelişir. ${ }^{[5]}$ Hem mekanik hem fonksiyonel instabilite kronik instabilite gelişmesinde rol oynar.

Kronik ayak bileği instabilitesi gelişen hastaların günlük aktivite düzeyinin belirlenmesi hem tanı hem de tedavi yönlendirmesi açısından çok önemlidir. Yüksek beklentileri olan ve kronik instabilitesi olan hastalarda cerrahi kararı almak daha kolaydır. Kronik instabilite dahi olsa özellikle günlük aktivite düzeyi düşük veya ciddi sporla uğraşmayan hastalarda peroneal kuvvetlendirme ve propriyosepsiyon egzersizleri ile pek çok hastada yüz güldürücü sonuç almak mümkün olabilir. Uygun konservatif tedaviye rağmen bulguları devam eden hastalarda ayak bileği stabilitesini sağlamak için cerrahi tedavi gereklidir. Cerrahiler, anatomik direkt tamir, non-anatomik bağ rekonstrüksiyonu veya artroskopik tedavi olarak sınıflandırılabilir.

Son yıllarda tartışılan bir diğer önemli konu da, üst düzey sporcuların ciddi burkulmalar sonrası gelişen akut dış yan bağ yaralanmalarının, kronik instabilite riskini azaltmak için akut cerrahi ile tedavi edilebileceğidir. Konservatif tedaviye rağmen bu hastalarda \%20'ye yakın subjektif instabilite kalabileceği bildirilmiştir. ${ }^{[1]}$ İnferior ekstansör retinakulumu kullanarak (Gould modifikasyonu) veya kullanmayarak yapılan anatomik tamir, kronik instabilitede ilk akla gelmesi gereken cerrahi tedavidir. Yaygın eklem gevşekliği veya bağ doku kaybı olanlarda bu tekniğin başarısı düşük olabilir.

Bu derlemenin amacı, son yıllarda ayak bileği dış yan bağ yaralanmaları sonrası spora dönüş ile ilgili yeni çıkan önerileri, kronik ve akut instabilitede kullanılan yeni cerrahi teknikleri ve sporculardaki akut bağ yaralanmasına yaklaşımdaki yeni yöntemleri gözden geçirmektir.

\section{HASTA DEĞERLENDIRMESi}

Kronik ayak bileği instabilitesi tanısı, ayak bileği ekleminde altı aydan daha uzun süren bir laksite durumu olduğunda konur. Bağ laksitesine, fizik muayene ve stres grafileri ile tanı koyabilmek mümkündür. Hastalar kötü bir burkulma sonrası tekrarlayan burkulmalar veya gevşeklik hissi ile başvurabilir. Bazı hastalar ağrı ve şişmeden şikâyetçidirler. Hastalardan, kısa ve uzun dönemde kaç kere burkulma yaşadıkları öğrenilmelidir. Hastalar güvensizlik ile de başvurabilirler. Bu güvensizlik hissi tibiotalar eklemden olabileceği gibi, subtalar eklemden veya her iki eklemden birlikte de kaynaklanabilir. Hastayı muayene ederken, mediyal ve lateral yapıları incelemek veya global gevşeklik açısından ön çekmece ve stres inversiyon testleri ile değerlendirmek gerekir (Şekil 1-3). Lateral instabilite, peroneal tendon yırtık veya subluksasyon/dislokasyonu ile birlikte seyredebilir. Tüm tendonlar fonksiyon ve güç açısından değerlendirilmelidir. Tüm alt ekstremitenin değerlendirilmesi gerekir. Kavovarus ayak yapısı açısından dikkatli olunmalıdır. Tüm muayenelerin karşılaştırılmalı yapılması gerekir. Fonksiyonel instabilitesi olan hastalarda; propriyoseptif sorunlar, peroneal kas güçsüzlüğü, tibiofibular yaralanmalar ve subtalar eklemde instabilite de düşünülmelidir.

Ayakta basarak ayak bilek ve ayak filmleri çekilmelidir. Özellikle, floroskopik muayene ile karşılaştırmaI olarak ayak bileklerinde ön çekmece ve inversiyon stres testi uygulamak ve dokümante etmek tanıda oldukça yararlıdır (Şekil 4-6). Floroskopide ön çekmece $10 \mathrm{~mm}$ 'den fazla, pozitif talar tilt de $9^{\circ}$ 'den büyük ise bu instabilite açısından destekleyicidir, ancak en iyisi karşı taraf ile mukayese etmektir. Ölçümler daha objektif olarak Telos cihazı ile de yapılabilir. ${ }^{[6]}$

Düz radyografinin dış yan bağ yaralanma tanısında yeri sınırlıdır, o nedenle manyetik rezonans (MR) görüntülemeye başvurmak gerekir. MR görüntüleme, bağ, peroneal tendon ve kondral lezyon patolojilerini ayırt etmek için kullanılabilir (Şekil 7). MR'nin ATF bağı görüntülemedeki hassasiyeti \%76-84 arasındadır. MR sayesinde, eşlik eden osteokondral lezyonlar, peroneal tendon sorunları, eklem fareleri de tespit edilebilir. Ultrasonografi (US) de kemik iskelet sistemi patolojilerinde gittikçe artan sıklıkta kullanılmaya başlanmıştır. ATF bağdaki uzama stres ön çekmece testi ile US eşliğinde dinamik olarak da görüntülenebilir. Ancak 


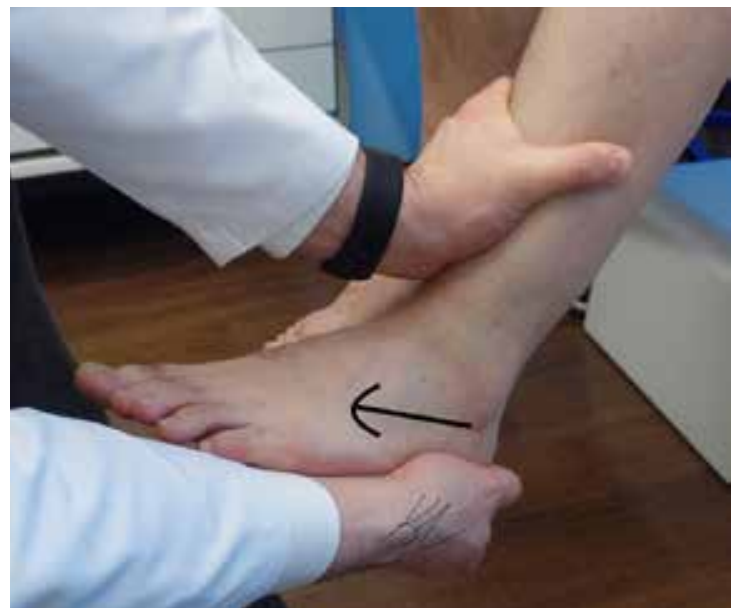

Şekil 1. Ön çekmece.

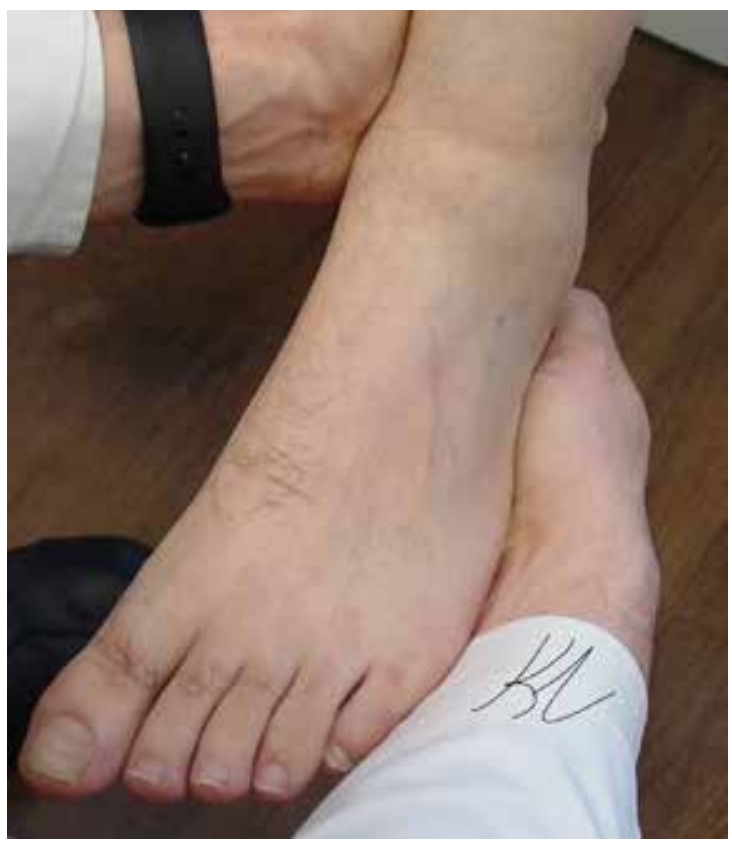

Şekil 2. Inversiyon zorlaması öncesi ayak nötralde.

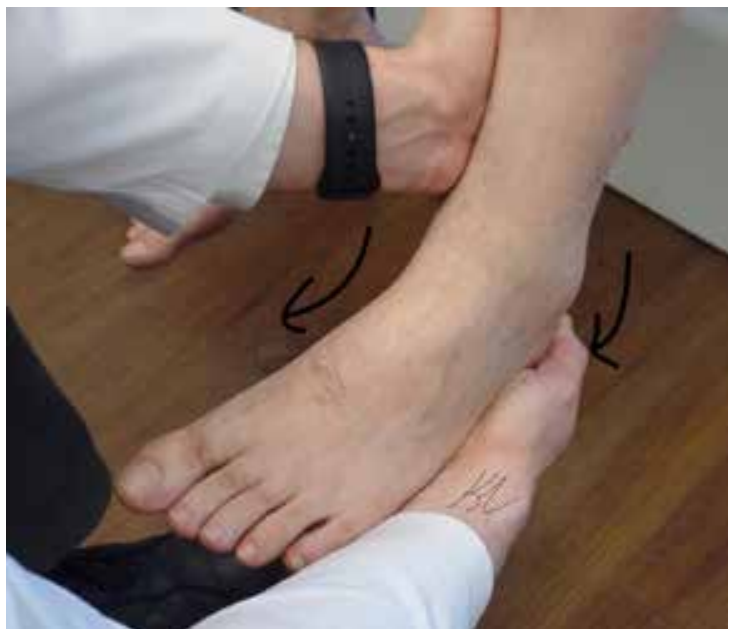

Şekil 3. İnversiyon stres zorlaması.
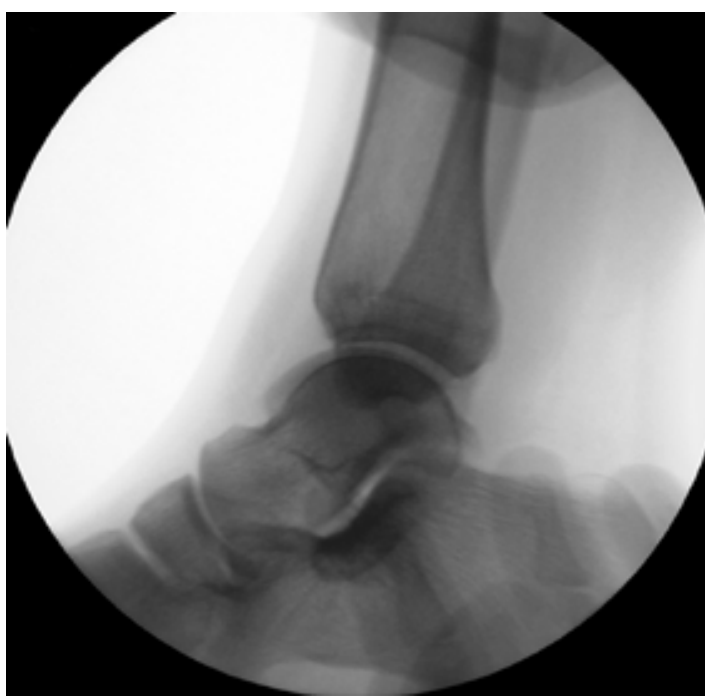

Şekil 4. Ön çekmece stres uygulanmadan önce floroskopik görüntü.

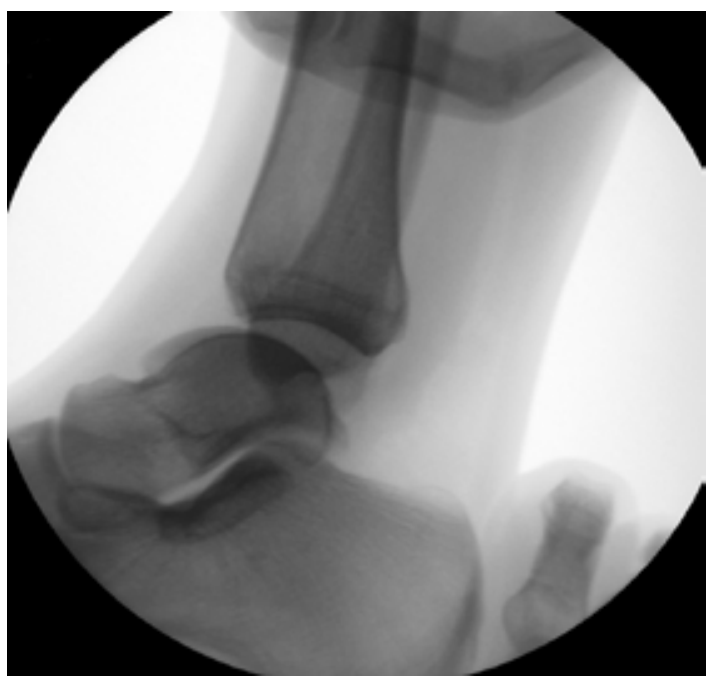

Şekil 5. Floroskopi altında ön çekmece zorlaması.

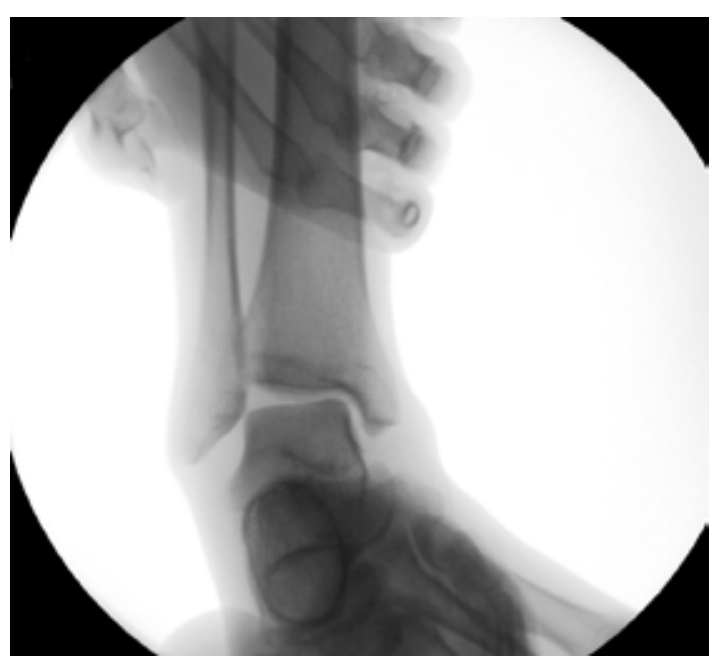

Şekil 6. Floroskopi altında inversiyon zorlaması, ATFL ve CFL yırtığına bağlı talotibial açıda açılma gözlenmekte. 


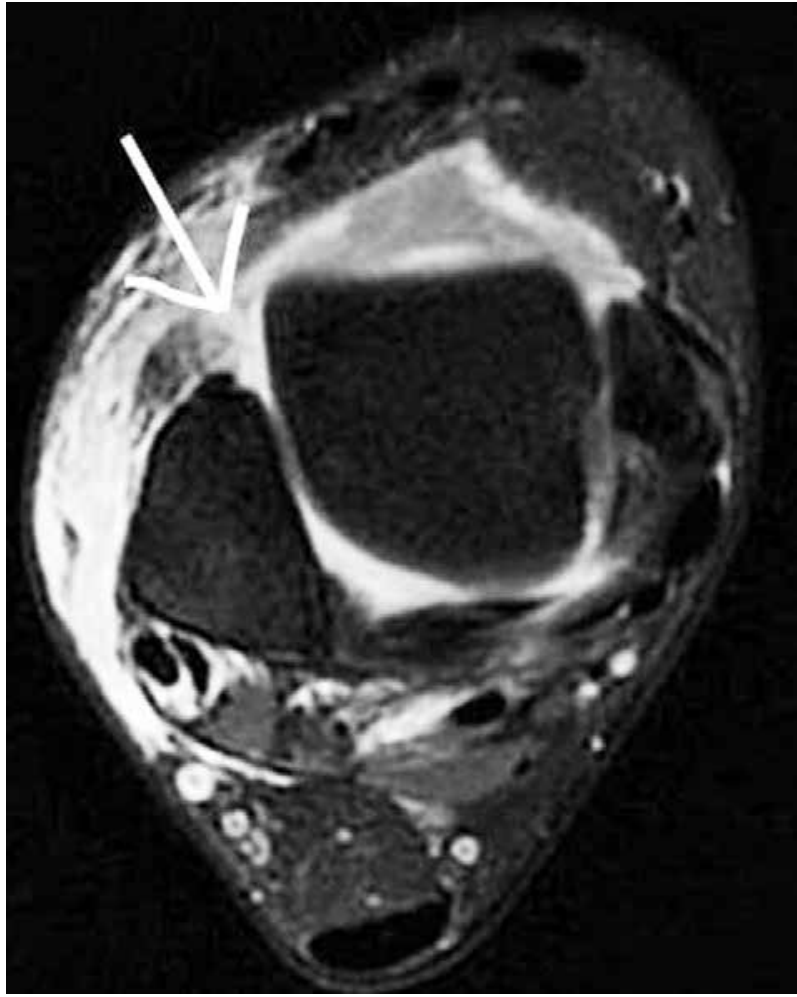

Şekil 7. T2 sekans aksiyel kesitte ATFL'nin yerinde olmadığı görülmekte.

US'den elde edilecek sonuç, her zaman olduğu gibi çekene bağlıdır.

\section{TEDAVi}

\section{Konservatif Tedavi}

Akut bağ yaralanmasında, konservatif tedavide erken dönemde PRICE (Protection, Rest, Ice, Compression, Elevation) uygulamasını takiben (yürüme botu veya kısa süreli alçı/atel uygulaması, koltuk değneği, buz ve elevasyonu içeren ilk 4-5 gün), hastalarda altı hafta ayak bileği stabilizasyon ortezi kullanmak, kronik instabilite gelişmesini engellemek için en ideal yöntemdir (Şekil 8). Buna mutlaka bir de uygun rehabilitasyon programı eklemek gerekir. Yaralanmanın 2. veya 3. haftasında ağrının da azalmasıyla, rehabilitasyona peroneal kuvvetlendirme eklenir. Kronik instabilitesi olup cerrahiye gidecek olan hastalarda da bu rehabilitasyonun yararı olabilir. Fizik tedavi, genellikle mekanik instabiliteden ziyade fonksiyonel instabiliteye etkilidir. Konservatif tedaviye, haftada üç günden altı haftaya kadar devam etmek gerekir.

Fizyolojik sınırlarda ayak bileği hareketi olan, ancak ayak bileğinde istemli kontrolü olmayan

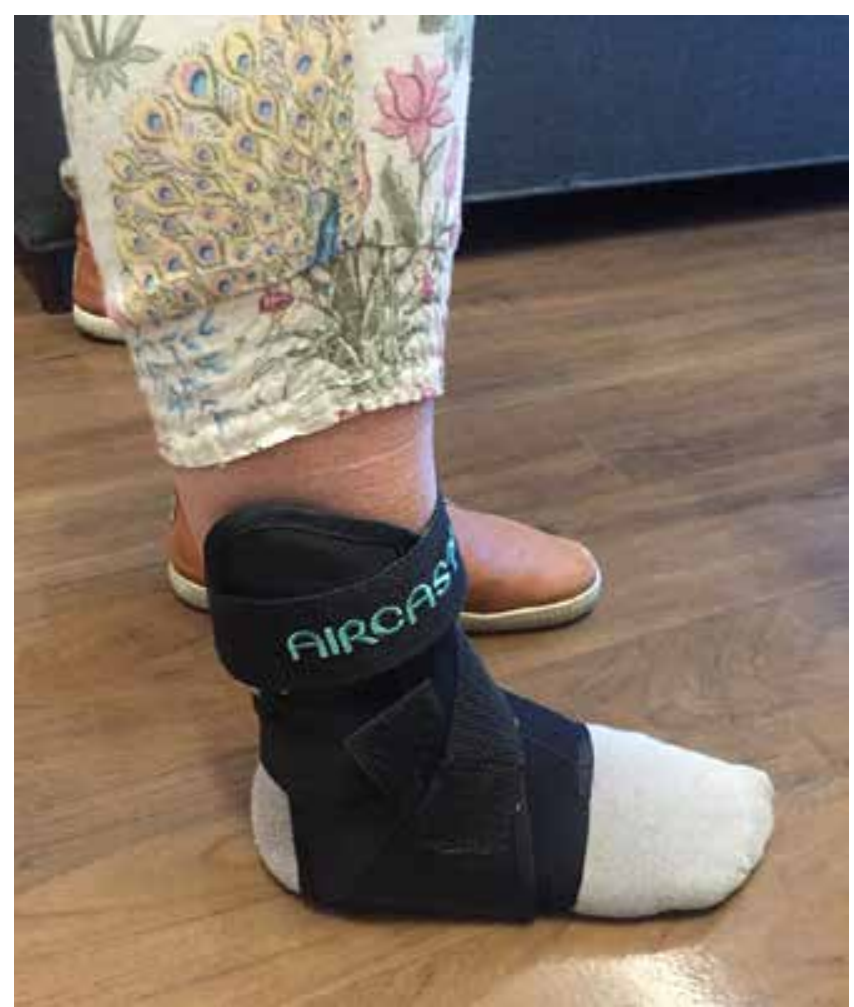

Şekil 8. Ayak bileği stabilizayon ortezi uygulanmış hasta. Ortezler spor yaparken ve ayakkabı ile giyilebilir.

fonksiyonel instabilite durumlarında da, hastalar propriyoseptif egzersiz ve kuvvetlendirmeden yarar görebilir. Ayak bileği burkulmaları sonrası peroneal tendonda artmış ateşleme gecikmesi, çalışmalarda gösterilmiştir. Bazı yazarlar mekanik instabilitesi olan hastalarda cerrahinin daha fazla gerekli olduğunu ileri sürseler de, bu iki tip instabilite birbirinden çok net sınırlar ile ayrılıp kategorize edilememektedir. Fonksiyonel veya mekanik olsun, kronik lateral bağ instabilitesi olan hastalarda cerrahi karar almadan önce herhangi bir tür fizik tedaviyi üç ay denemek gerekir.

\section{Cerrahi Teknikler}

\section{Non-anatomik teknikler}

Tarihsel olarak, dış yan bağ onarım teknikleri anatomik ve anatomik olmayan olarak ikiye ayrilır. Chrisman-Snook ve Watson-Jones gibi anatomik olmayan cerrahi işlemler ile kısa dönemde iyi sonuçlar alınmış olunsa da, özellikle uzun dönemde hastalar ayak bileklerini daha sıkı hissettiklerini belirtmişlerdir. Karşılaştırmalı çalışmalarda, anatomik olmayan işlemlerin daha başarısız oldukları gösterilmiştir. ${ }^{[7,8]}$ 


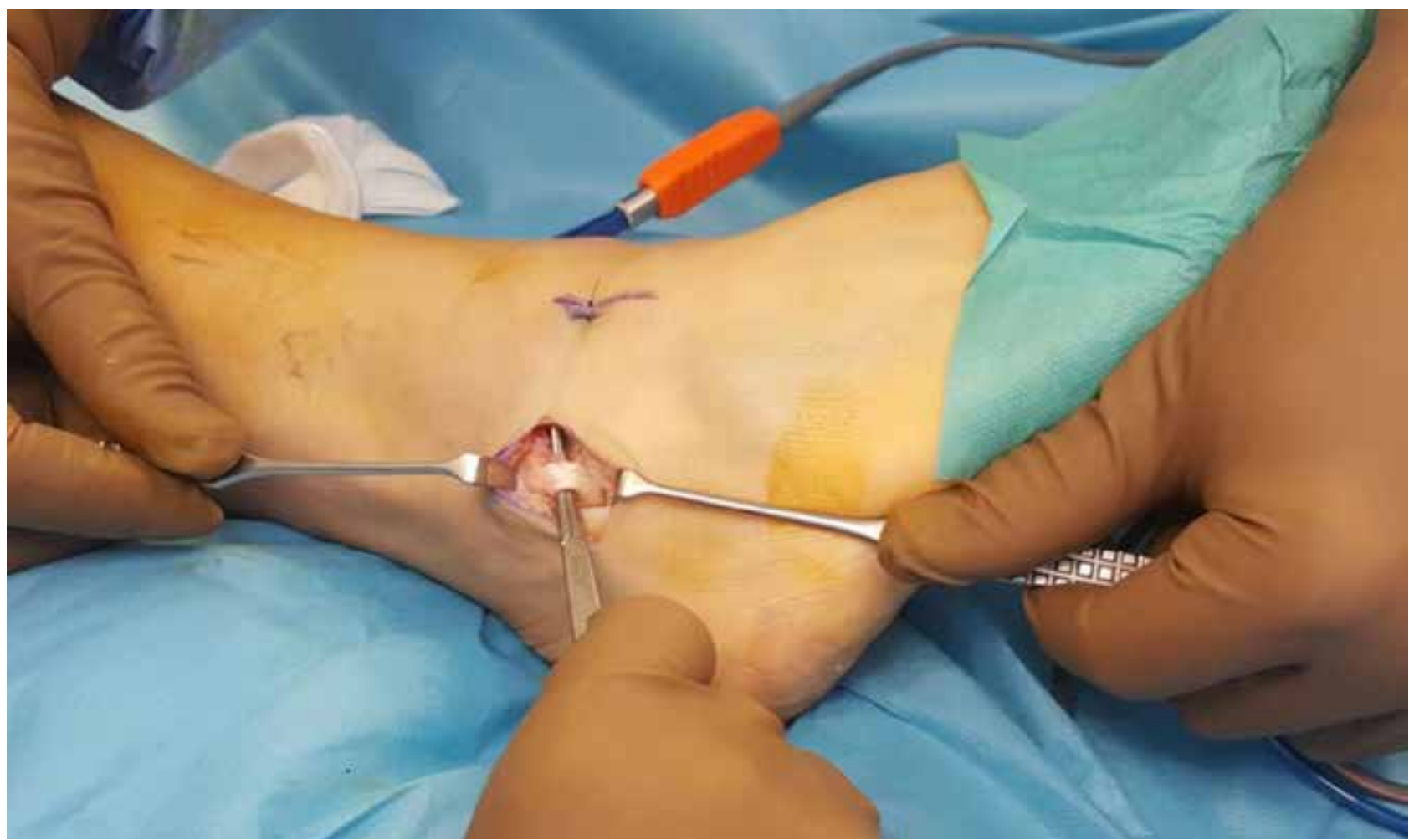

Şekil 9. Uzamış CFL ameliyat görüntüsü.

Sammarco da, anatomik olmayan teknikler ile daha çok yara komplikasyonu göstermiş̧ir..$^{[9]}$

\section{Anatomik teknikler}

Anatomik prosedürler, çalışmayan ATFL veya CFL'nin direkt tamir edilmesi veya otogreft veya allogreft ile anatomik olarak rekonstrükte edilmesidir. Bağ dokusu yeterli olan hastalarda anatomik tamir endike iken, obez hastalar, jeneralize laksitesi olanlar veya önceden başarısız cerrahi geçiren hastalar gibi kalan bağ dokusu yetersiz hastalarda rekonstrüksiyon uygulamak gerekebilir. ${ }^{[10]}$

Hem ATFL hem CFL yaralanması olan hastalarda CFL'nin tamir edilip edilmemesi gerektiği de tam netlik kazanmamıştır. CFL, subtalar eklemin primer stabilizatörüdür ve bu bağın yaralanması subtalar instabilite yapabilir. Ancak, Wang ve ark. kalkaneus kırık cerrahi tedavisi sonrası kesilen CFL'nin instabiliteye yol açmadığını göstermiştir. ${ }^{[11]}$ Mafulli ve ark. da, izole ATFL tamiri sonrası dokuz yıl takip ettikleri hastalarda, CFL tamirine gerek olmadan AOFAS (American Orthopaedic Foot and Ankle Society) skorlarının yeterli seviyeye çıktığını ve hastaların tatmin olduğunu bildirmişlerdir. ${ }^{[12]}$
Lateral bağ yaralanmalarının cerrahi tedavisinde anatomik direkt tamir, altın standart olarak kabul edilen ve en sık kullanılan cerrahi yöntemdir. Broström ameliyatı ve Gould modifikasyonu en sık uygulanan anatomik tamir teknikleridir. Bir diğeri ise Karlsson modifikasyonudur. ${ }^{13]}$

Kronik instabilite durumunda genellikle, ATFL yırtık değil, sünmüş veya uzamış olarak bulunur. Aynı şekilde eğer CFL de yaralanmış ise morfolojik görüntüsü uzamış bağ şeklinde olur (Şekil 9). Ancak, ilerleyen dönemlerde bazı hastalarda hiç bağ dokusu kalmamış olabilir; bu hastalarda anatomik bağ tamiri yerine rekonstrüksiyon tekniklerinden birini düşünmek gerekir. Broström ameliyatı, bu kalan uzamış bağ dokunun fibular taraftan kesilmesi ve kemik kanlandırıldıktan sonra bir çapa veya direkt olarak vest-over-pants (pantalon üzerinde duran yeleğe benzediğinden) tekniği şeklinde dikilmesi ile uygulanır. ${ }^{[14]}$ Çapa ile yapılan tespitlerin daha sağlam olduğu gösterilmiştir. Lokal bir doku parçası olan ekstansör retinakulumun parsiyel olarak bu dikişi desteklemek için kullanılması ise Gould modifikasyonudur. ${ }^{[15]}$ Gould makalesinde, bu teknik sonrasında hastalarına dört hafta yürüme alçısı uyguladığını ve sonrasında ilk iki hafta inversiyon ve eversiyona başladığını bildirmiştir. Teorik olarak, inferior retinakulum 
CFL vektörünü desteklemektedir. Biyomekanik olarak, inferior retinakulum ile yapılan destek erken dönem bağ kuwvetini de arttırmaktadır. ${ }^{[16]}$

Broström-Gould ameliyatını fonksiyonel sonuçları oldukça yüz güldürücüdür. Bell ve ark., 22 hastayı 26,3 yıl takip etmiş ve fonksiyonel skorları 100 üzerinden 91,2 olarak bulmuştur. ${ }^{17]}$ Tourné ve ark., 150 hastayı 11 yıl takip etmiş ve \%93 tatminkar sonuç bulmuşlardır. ${ }^{[18]}$ Li ve ark.'nın geriye dönük olgu serisinde, 52 üst düzey sporcunun 49'u iki yıl içinde ameliyat öncesi performansına dönmüştür. ${ }^{[19]}$ Bu teknikler; düşük maliyetleri, minimal invaziv olmaları, düşük komplikasyon oranları ve teknik olarak basit olmaları nedeniyle oldukça avantajlıdır ve tercih edilmektedir. ${ }^{[13]}$

Sonuçlar yüz güldürücü olsa da, geç dönemde bağ tamiri sonrası gevşeme gösteren çalışmalar da mevcuttur. Mafulli ve ark., dış yan bağ yaralanması olan 42 sporcuya ayak bileği artroskopisi ve Broström ameliyatı yapmış ve ortalama 8,7 yıl takip etmişlerdir. ${ }^{[12]}$ Hastaların son takiplerinde, AOFAS ve Kaikkonen skorlarında anlamlı bir düzelme tespit etmişlerdir. \%58(12) hasta ameliyat öncesi spor seviyelerine dönebilmiş, \%16(6) daha düşük seviyede devam edebilmiş, $\% 10(26)$ hasta spora devam edememiş, altı hastada ise instabilite tekrarlamıştır. Sonuçta yazarlar, Broström ameliyatını hem etkin bulmuşlar hem de genel olarak spora dönüşün mümkün olduğunu göstermişlerdir. Ancak, \%16'lık yüksek rekürrens araştırmacıları yeni teknikler bulmaya da itmiştir. Bunlardan birisi, Broström ameliyatının InternalBrace ${ }^{\circledR}$ (Arthrex Inc., Naples, FL, USA) denilen biyokompozit iki vida arasında uygun şekilde gerilmiş kalınca bir fiber tape ip desteğinin tamiri desteklemek için kullanılmasıdır. ${ }^{[20-24]}$ Standart Broström ameliyatı doğal dokunun matürasyonuna bağlı olduğu için, ameliyat sonrası rehabilitasyona başlamadan önce yaklaşık altı hafta immobilizasyon gerektirmektedir. Sporcuların sahaya dönüşü öncesi dokuların kuvvetlenmesi 3-6 ayı bulabilmektedir. Ancak fiber tape şeklinde bir destek kullanmak, özellikle sporcularda sahaya dönüşü hızlandırabilmektedir. ${ }^{[25]}$ Coetzee ve ark., InternalBrace ${ }^{\circledR}$ kullanarak Broström ameliyatı yaptıkları 81 dış yan bağ instabilitesi hastasını yaklaşık iki yıl takip etmişlerdir. Bu hastalara AOFAS, VR-12, FAAM ve VAS skorlamaları yapmışlar ve ameliyat süresi, sahaya dönüş gibi parametreleri incelemişlerdir. Ortalama spora dönüşü 84,1 gün, AOFAS skorunu ise ortalama 94,3 bulmuşlardır. InternalBrace ${ }^{\circledR}$ uygulamanın ameliyata $10 \mathrm{dk}$ eklediğini ve cerrahi tekniğin güvenle kullanılabileceğini göstermişlerdir. ${ }^{[25]}$ Ancak unutulmamalıdır ki, InternalBrace ${ }^{\circledR}$ implantı bu teknikte bir destek implant olarak kullanılmakta, doğal bağın yerini tutmamaktadır (Şekil 10-12).

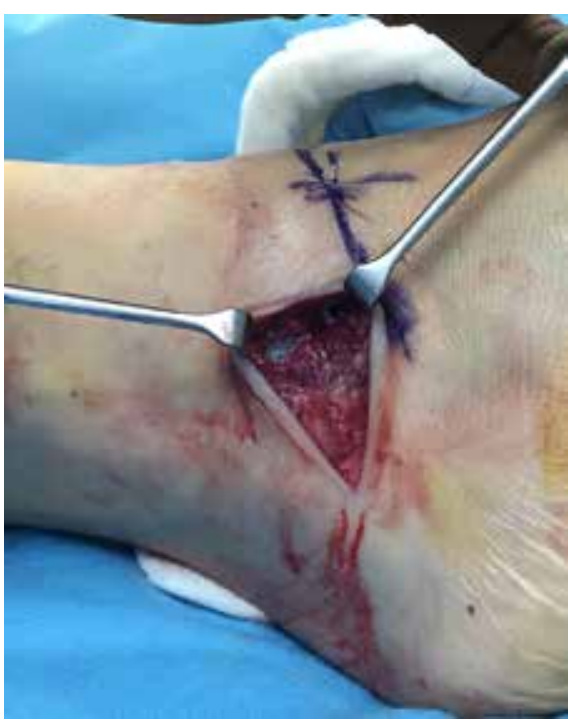

Şekil 10. InternalBrace ${ }^{\circledR}$ ile desteklenmiş anatomik tamir. Minimal invaziv kesiden yapılmış ameliyat.

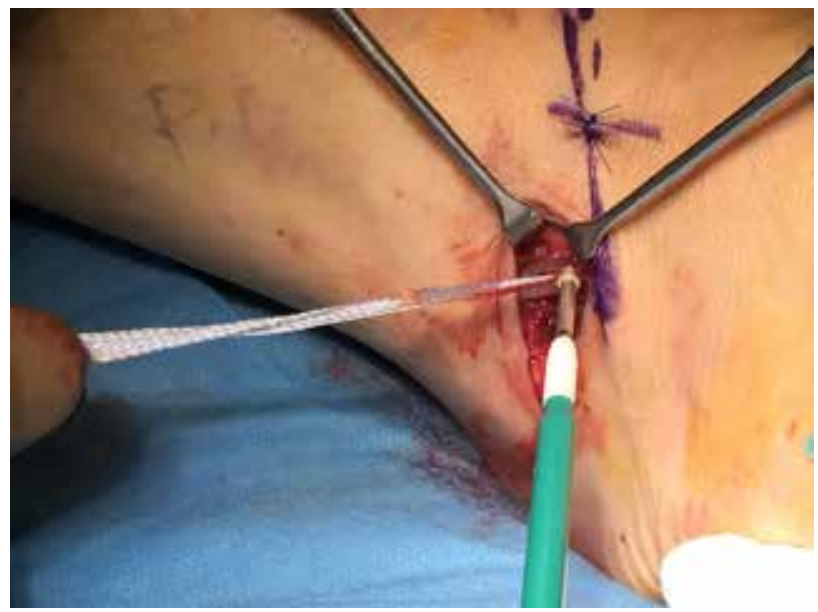

Şekil 11. Talusa swivelock yerleştirilmesi, InternalBrace ${ }^{\circledR}$ uygulaması.
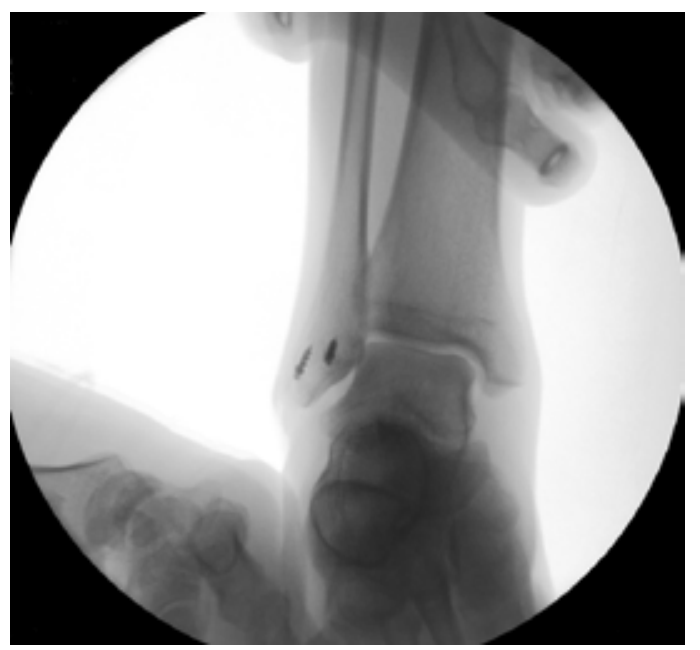

Şekil 12. ATFL anatomik tamiri ve InternalBrace ${ }^{\circledR}$ uygulaması sonrası floroskopi altında inversiyon zorlamasında ayak bileğinin açılmadığı gözlenmekte. 
Bu implant, dizde patella çıkıklarının tespiti veya mediyal kollateral bağ tamirinin desteklenmesi için bir süredir kullanılmaktadır. ${ }^{[26-28]}$ Bir biyomekanik çalışmada, yazarlar InternalBrace ${ }^{\circledR}$ kullanılarak rekonstrükte edilmiş ATFL ile doğal ATFL'yi 12 kadavra üzerinde, tibiaya iç rotasyon zorlaması yaptırarak test etmişlerdir. Ayak bileği doğal lateral bağı ile bu implant karşılaştırıldığında, InternalBrace ${ }^{\circledR}$ uygulanmış grup ile doğal bağ arasında kopmaya karşı dirençler eşit bulunmuştur. ${ }^{[22]} 2015$ yılında Giza ve ark. ise, 10 kadavra üzerinde yaptıkları biyomekanik karşılaştırmalı çalışmalarında, \#0 FiberWire ile desteklenmiş artroskopik tamirleri izole artroskopik tamirler ile karşılaştırdıklarında, güç ve dayanıklılık açısından fark bulamamışlardır. ${ }^{[29]}$ InternalBrace ${ }^{\circledR}$ uygulaması, ultra yüksek molekül ağırlıklı polietilen/ polyester ip tape'lerin ve düğümsüz kemik çapaların ikincil bir destek olarak kullanıldığı, bu nedenle hem spora dönüşü hızlandıran hem de rekürrensi azaltabilen bir teknik olabilir; ancak henüz endikasyonları ve uzun dönem sonuçları bilinmemektedir. Her bağ tamirinde kullanılmasını destekleyen çalışma henüz yoktur. Günümüz itibariyle; hiperlaksite, obezite ve sporcularda kullanılması daha uygun gibi gözükürken, ileriye dönük randomize klinik çalışmalar ile yeni kullanım alanları ortaya konabilecektir.

Artroskopik tekniklerin gelişmesine paralel olarak, bu implant artroskopik olarak da yerleştirilmeye başlamış ve açık teknikler ile benzer başarı elde edilmeye başlanmıştır. ${ }^{[30]}$ Yoo ve ark., 85 hastaya artroskopik Broström ameliyatı uygulamışlardır; bunların 22'sine InternalBrace ${ }^{\circledR}$ uygulamış ve 63 tanesine uygulamamışlardır. InternalBrace ${ }^{\circledR}$ uyguladıkları grupta daha erken yük vermişler ve daha erken ayak bileği hareketleri başlamışlar, sonuçta spora erken dönüş beklentisi olan hastalarda InternalBrace ${ }^{\circledR}$ ile desteklemeyi önermişlerdir. ${ }^{\left[{ }^{30]}\right.}$ Birden çok araştırma$\mathrm{cl}$, artroskopik teknikler ile başarılı sonuçlar yayımlamıştır. ${ }^{[31,32]}$ Ancak, artroskopik anatomik tamiri ilk tanımlayan Lui ve ark. yanı sıra bazı diğer yazarlar, açık tekniklere göre daha fazla komplikasyon olabileceğini söylemişlerdir. ${ }^{[33,34]}$ Artroskopik olarak ayak bileği dış yan bağlarına termal büzüştürme (shrinkage) tekniği uygulamış ve kısa orta vadede kabul edilebilir sonuçları olduğunu ileri sürmüşlerdir. ${ }^{[35,36]}$ 2017 yılında yapılan bir çalışmada ise, fonksiyonel sonuçlardaki iyileşmeye ve hasta tatmininin iyi olmasına rağmen bu tekniğin rekürrens açısından riskli olduğu ve kronik bağ instabilitesi olan hastalarda bu tekniğin önerilmediği bildirilmiştir. ${ }^{[37]}$ Cottom ve Rigby, aynı teknik ile 40 hastayı tamamen artroskopik ameliyat edip ortalama bir yıl takip etmiş ve AOFAS skorlarında belirgin iyileşme ve klinik olarak da negatif ön çekmece testi ve mükemmel stabilite bildirmişlerdir. ${ }^{[32]}$ Ayak bileği artroskopisi ile ilgili olarak, artroskopik anatomi, bağ anatomisi ve güvenli alanlar ortaya kondukça, artroskopik kronik bağ tamirlerine de son yıllarda ilgi artmıştır. ${ }^{[38]}$ Bazı yazarlar bu tekniğe 'ArthroBroström' de demektedir ve diz ve omuz çıkığında olduğu gibi ayak bileğinde de kronik bağ yaralanmalarının esas tedavisinin artroskopik olup olmayacağını zaman içinde yapılacak çalışmalar gösterecektir (Şekil 13-15). ${ }^{[39,40]}$

Artroskopik teknikleri biraz daha ileriye taşıyan, tamamen artroskopik olarak semitendinozus allogreft ile rekonstrüksiyonun mümkün ve başarılı olabileceğini gösteren çalışmalar da vardır. Bu çalışmalarda, 12 ay takip edilen hastalarda, anatomik tamir ile rekonstrüksiyonu karşılaştırılmış ve hastalarda \%8,3-12,5 arası değiş̧en oranlarda ayağın dış yanında hissizlik saptanmış, ancak rekürrens veya başka komplikasyon yaşanmadığı bildirilmiştir. ${ }^{41]}$

ESSKA-AFAS (European Society for Sports Traumatology, Knee Surgery and Arthroscopy - Ankle and Foot Associates) ayak bileği instabilite grubunun 2016 yılında yaptığı sistematik derleme göstermiştir ki minimal invaziv ve artroskopik ayak bileği kronik bağ cerrahileri ile ilgili literatürdeki çoğu yayın, 4. veya 5 . seviyedir ve henüz bu konu ile ilgili yeterli çalışma bulunmamaktadır. ${ }^{[42]}$

Artroskopik teknikler ile ilgili bir diğer soru da, her açık anatomik tamir ameliyatında ayrı bir işlem olarak uygulanması mı gerektiğidir. Bazı yazarlar, her anatomik tamirde artroskopi ile eklem içine bakmanın olası kondral lezyonları değerlendirmek ve eklem farelerini tespit için gerekli olduğu söylerken, bazıları sadece ağrısı olan hastalarda kullanmaktadırlar.

\section{Anatomik Bağ Rekonstrüksiyonu}

Özellikle iri sporcular ve revizyon olgularında, hiperlaksitesi olanlarda, ardayak varusu olanlarda ve yetersiz rezidüel dokusu kalanlarda, allogreft veya otogreft ile anatomik rekonstrüksiyon önerilmektedir. ${ }^{[43]}$ Jeneralize hiperlaksitesi olanlarda anatomik tamir ile başarı şansının düşük olduğu gösterilmiştir. ${ }^{[44]}$ Stres filmlerinde $20^{\circ}$ 'den fazla varus ve 14 mm'den fazla öne translasyon olan hastalarda endikedir. Otogreft, allogreft, greft tespit seçenekleri ve teknik ayrıntıları birbirinden farklı pek çok metod tanımlanmıştır. ${ }^{[45-48]}$

Kim ve ark., 2015 yılında yayımladıkları çalışma$\mathrm{da}$, minik pencerelerden peroneus longus tendonun ön yarısını aldıktan sonra ATFL ve CFL rekonstrüksiyonunda kullanmış ve \%81 mükemmel veya iyi sonuç bulmuşlardır. ${ }^{[49]} \mathrm{Bu}$ çalışmada, 34 hastanın 


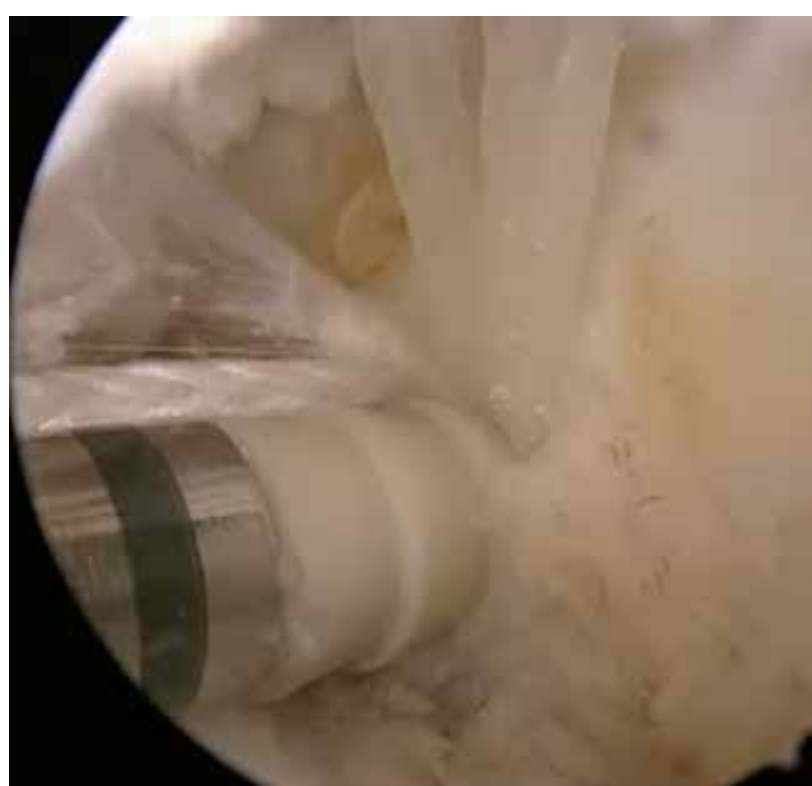

Şekil 13. Artroskopik swivelock yerleştirilmesi. (Doç. Dr. Barış Kocaoğlu'nun arşivinden)

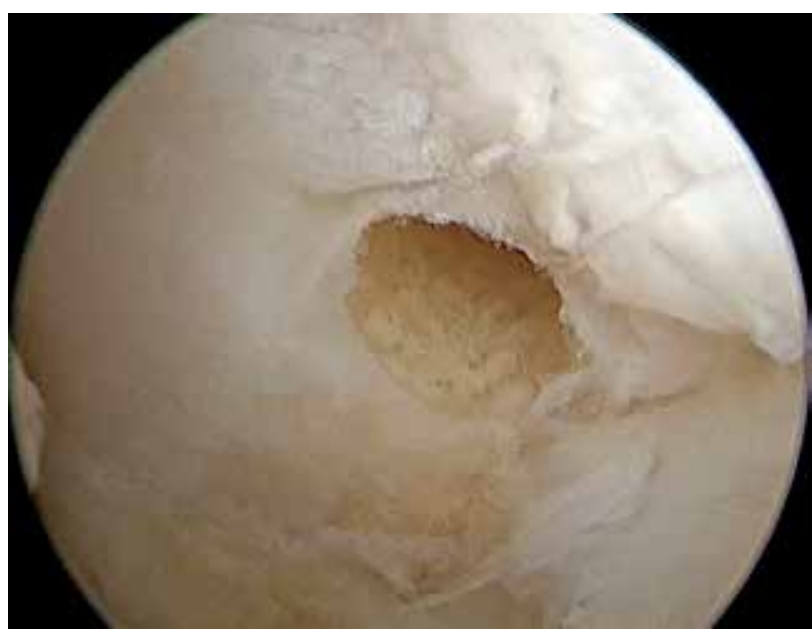

Şekil 14. Talusta açılan tünel.

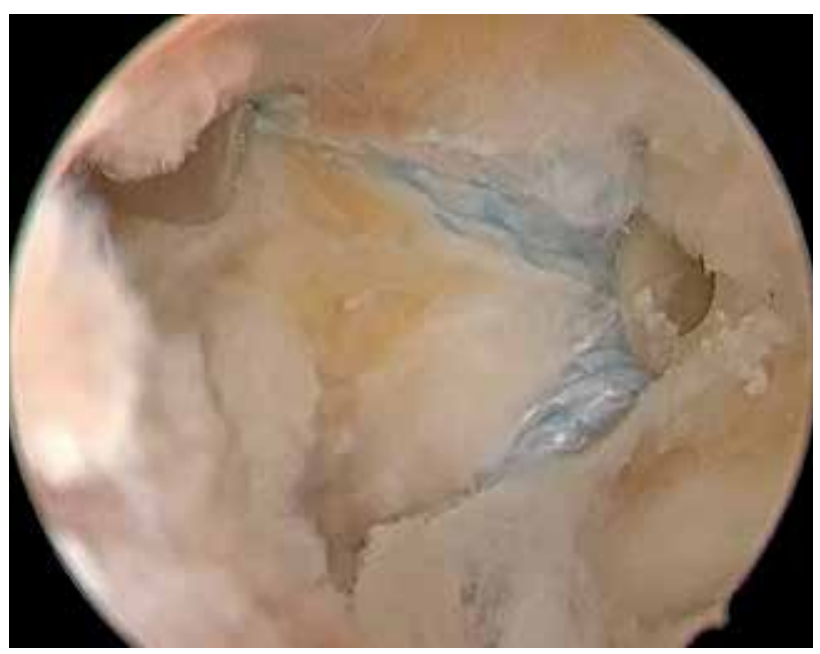

Şekil 15. InternalBrace ${ }^{\circledR}$ talusa yerleştirilmiş. hepsinde çok belirgin bir komplikasyon görülmeden mekanik stabilite kazanılmıştır. Park ve ark., biraz daha farklı bir teknik ile aldıkları peroneus longus tendon otogrefti ile hiç donör saha morbiditesi ve komplikasyonu yaşamadıklarını belirtmişlerdir. ${ }^{[50]}$ Sun ve ark. da, kronik ayak bileği instabilitesinde subtalar ve Chopart ekleminin instabilitenin oluşumuna katkıda bulunduğunu belirterek, bu iki eklemin yine peroneus longus otogrefti ile anatomik rekonstrüksiyonunu önermişlerdir. Kendi serilerinde, 32 hastada ağrı, AOFAS ve Karlsson skorlarında iyi sonuçlar bildirmişlerdir. ${ }^{[51]}$ Anatomik tamir ve rekonstrüksiyonların anatomik olmayan teknikler ile karşılaştırıldığı sistematik derlemede, 19 makale ve 882 hastanın değerlendirilmesinden sonra Vuuberg ve ark., anatomik tekniklerin fonksiyonel açıdan belirgin olarak daha iyi olduğunu bulmuşlardır. [52] Krips ve ark.'nın çok merkezli çalışmasında da, 2-10 yıllık takiplerde anatomik rekonstrüksiyonun çok daha başarılı olduğu vurgulanmıştır. ${ }^{[53]}$

Robert Anderson'un grubu, peroneus brevis ön 1/3'ü ile Broström üstüne rekonstrüksiyon uygulamış ve tekniklerini 2016'da yayımlamışlardır. Bu tekniği uyguladıkları 19 hastayı beş yıl takip etmişler ve ayak bileğinde azalmış hareket, peroneal kas gücünde hafif azalma dışında, rekürrens instabilite veya progresif dejeneratif değişiklikler kaydetmediklerini bildirmişlerdir. ${ }^{[54]}$

\section{Kronik Ayak Bileği Cerrahi Tedavisinde Artroskopik Değerlendirme}

Başarılı bağ rekonstrüksiyonları sonrası \%13-35 hastada semptomların devam ettiği tespit edilmiştir. ${ }^{[55-57]}$ Bazı yazarlarca, semptomların devam etmesinde eklem içi gözden kaçan patolojilerin varlığı suçlanmış, bu nedenle cerrahi esnasında bağ tamirine artroskopik değerlendirmenin de eklenmesi önerilmiştir. ${ }^{[55-57]}$ Bunun yanı sıra bazı yazarlar, hastaların ameliyat öncesi ayak bileği ağrıları varsa, artroskopi eklenmesinin uygun olduğunu, gereksiz yapılan artroskopinin doku aralarına su sızmasına neden olarak ameliyatı teknik olarak zorlaştırabileceğini belirtmişlerdir. Kronik bağ yaralanması olan hastalarda ameliyat sonrası ağrı devam ediyorsa; talus osteokondral lezyonları, yumuşak doku sıkışmaları, eklem fareleri veya peroneal tendon problemleri akla getirilmelidir. Choi ve ark., 65 ayak bileği instabil hastanın 63'ünde yumuşak doku sıkışması, \%23,1 hastada da osteokondral lezyon varlığı tespit etmişler. ${ }^{[58]}$

Kronik ayak bileği instabilitesi olan hastalarda, zaman zaman lateral malleol distal tipinde osseöz kemik avulsiyon parçaları da bulunabilmektedir. 
Bu parçaların varlığının veya büyüklüğünün sonuçlar ile ilişkisi henüz anlaşılamamakla birlikte, büyük parçaların eksizyonu Broström ameliyatını zorlaştırabileceği için başka rekonstrüksiyon yöntemleri önerilmektedir. Ameliyat öncesinde kalan ATFL artıklarının anatomik tamir için yeterli olup olmadığını anlamak için de artroskopi yapılmasını öneren yazarlar mevcuttur. Bu nedenle, klinik ve radyolojik incelemelerin dışında, ağrısı ve radyolojik bulgusu hiç olmayan hastaların dışında kalan hastalara, bağ ameliyatına ek artroskopi rutin olarak eklenebilir. Bu artroskopide; yumuşak doku sıkışması, osteokondral lezyonlar, sindezmozda ayrışma ve kalan ATFL'nin yeterli olup olmadığı incelenmelidir.

\section{Sporcularda Akut Ayak Bileği Bağ Tamiri}

Son yıllarda tartışılan bir diğer konu da, sporcularda akut bağ yaralanmalarında akut tamirin sonuçlara olan etkisidir. Günümüzde çoğu sporcunun akut dış yan bağ yaralanması konservatif tedavi edilmekte, ancak kronik bağ sorunları veya bağ laksitesi varsa cerrahi yapılmaktadır. Konservatif tedavi sonrası uzun dönemde bazı hastalarda fonksiyonel instabilite gelişebildiği de bilinmektedir. Bu nedenle, günümüzde bazı yazarlar üst düzey beklentisi olan sporcularda akut tamiri önermektedirler. ${ }^{\left[{ }^{[9-62]}\right.}$

Sistematik derlemeler, sporcularda Evre 3 bağ yaralanmalarında konservatif tedavinin cerrahi tedaviye üstün olduğunu gösterememiştir. Yapılan çalışmalar, cerrahinin daha çok komplikasyonlu ve daha maliyetli olduğunu göstermiştir. Ancak, yüksek düzey sporcular için önemli olan, sahaya erken dönüş ve kalıcı sorunların kalmamasıdır. Günümüzde 20-30 yıl önceki gibi uzun süreli alçı tespitleri yapılmamaktadır ve rehabilitasyon protokolleri değişmiştir. Daha önceleri Broström ameliyatı yapılmış hastalar altı hafta alçıda tutulurken, bir hafta alçı uygulamasını takiben yürüme botuna geçilmekte ve erken harekete başlanmaktadır. InternalBrace ${ }^{\circledR}$ uygulaması bu protokoleri daha da hızlandırmaktadır. Bu nedenle, cerrahi riskler bir yana konulduğunda ameliyat sonrası kalıcı instabilite riski daha az olduğundan, bazı cerrahlar akut bağ yaralanmalarında cerrahi tedaviyi önermekte ve bu ameliyatların da tecrübeli cerrahlar tarafından yapılmasının başarılı sonuçlar almak açısından daha etkin olduğunu ileri sürmektedirler. ${ }^{[63]} \mathrm{Bir}$ geriye dönük çalışmada, White ve ark. 42 sporcuya Broström ameliyatı yapmış ve iki yıl takipleri sonucunda hastaların üç ayda spora dönebildiğini göstermişlerdir. Hiçbir hastalarında tekrarlayan instabilite gelişmemiştir. ${ }^{[59]}$

\section{SPORA DÖNÜŞ}

Dış yan bağ rekonstrüksiyonlarının sonuçları oldukça tatminkârdır. ${ }^{63]}$ Mafulli ve ark.'nın uzun dönemli takiplerinde; hastaların \%58'i eski seviyelerinde spora dönebilmiş, \%16'sı bir alt seviyede dönerken, \%26'sı aktif olmaya devam etmiş, ancak sporu bırakmak zorunda kalmıştır. ${ }^{[12]}$ Benzer şekilde Nery ve ark. da, artroskopik Broström tamiri sonrası 9,8 yıllık takiplerinde, dış yan bağ tamiri sonrası spora dönüşün sindezmoz yaralanmasından daha önce ve daha olası olduğunu belirtmişlerdir. ${ }^{[64]}$ Coetzee ve ark., \%86,4 hastanın normal veya normale yakın fonksiyona döndüğünü göstermiştir. ${ }^{[25]}$ Başka bir çalışmada, artroskopik tamir yapılan 21 kronik bağ instabilitesi olan hastaların tamamı 21,5 hafta sonra spora dönmüşlerdir. ${ }^{65]}$

\section{SONUÇ}

Günümüzde ayak bileğinin akut ve kronik dış yan bağ yaralanmalarında ilk uygulanması gereken tedavi erken fonksiyonel rehabilitasyona imkan verecek bir yöntem olmalıdır. Seçilmiş profesyonel oyuncularda akut cerrahi bir seçenek olabilir, ancak bu metod için yeterli kanıt düzeyi henüz yoktur. Kronik instabilitesi olan hastaların \%80 kadarı konservatif tedaviye iyi yanıt verirken, bazı hastalarda cerrahi gerekmektedir. Günümüzde altın standart Broström-Gould modifikasyonu gibi gözükmektedir. Laksitesi olan, iri hastalarda fiber tape bir destek kullanmak, rehabilitasyonu hızlandırmaktan ziyade tespitin dayanıklılığını arttırmak için gerekli olabilir. InternalBrace ${ }^{\circledR}$ uygulamaları özellikle sporcularda sahaya dönüşü belirgin olarak hızlandırmaktadır. Artroskopik anatomik tamir ise süre olarak açık ameliyattan daha uzun sürmektedir ve ciddi bir öğrenme eğrisi vardır; halen sadece çok tecrübeli birkaç yazarın standart tekniği olarak kullanılmaktadır, ancak her artroskopik teknik gibi gelişmeye açıktır.

\section{KAYNAKLAR}

1. DiGiovanni CW, Brodsky A. Current concepts: lateral ankle instability. Foot Ankle Int 2006;27(10):854-66. Crossref

2. Freeman MA, Dean MR, Hanham IW. The etiology and prevention of functional instability of the foot. J Bone Joint Surg Br 1965;47(4):678-685.

3. Pijnenburg AC, Van Dijk CN, Bossuyt PM, Marti RK. Treatment of ruptures of the lateral ankle ligaments: a metaanalysis. J Bone Joint Surg Am 2000;82(6):761-73.

4. McKay GD, Goldie PA, Payne WR, Oakes BW. Ankle injuries in basketball: injury rate and risk factors. $\mathrm{Br} J$ Sports Med 2001;35(2):103-8.

5. Hiller CE, Kilbreath SL, Refshauge KM. Chronic ankle instability: evolution of the model. J Athl Train 2011;46(2):133-41. Crossref 
6. Russo A, Giacchè $P$, Marcantoni $E$, Arrighi $A$, Molfetta L. Treatment of chronic lateral ankle instability using the Broström-Gould procedure in athletes: long-term results. Joints 2016;4(2):94-7. Crossref

7. Hennrikus WL, Mapes RC, Lyons PM, Lapoint JM. Outcomes of the Chrisman-Snook and modified-Broström procedures for chronic lateral ankle instability: A prospective, randomized comparison. Am J Sports Med 1996;24(4):400-4. Crossref

8. van der Rijt AJ, Evans GA. The long-term results of WatsonJones tenodesis. J Bone Joint Surg Br 1984;66(3):371-5.

9. Sammarco VJ. Complications of lateral ankle ligament reconstruction. Clin Orthop Relat Res 2001;(391):123-32.

10. Dierckman BD, Ferkel RD. Anatomic Reconstruction With a Semitendinosus Allograft for Chronic Lateral Ankle Instability. Am J Sports Med 2015;43(8):1941-50. Crossref

11. Wang CS, Tzeng $\mathrm{YH}$, Lin CC, Huang CK, Chang MC, Chiang CC. Radiographic Evaluation of Ankle Joint Stability After Calcaneofibular Ligament Elevation During Open Reduction and Internal Fixation of Calcaneus Fracture. Foot Ankle Int 2016;37(9):944-9. Crossref

12. Maffulli N, Del Buono A, Maffulli GD, Oliva F, Testa V, Capasso G, Denaro V. Isolated anterior talofibular ligament Broström repair for chronic lateral ankle instability: 9-year follow-up. Am J Sports Med 2013;41(4):858-64. Crossref

13. Yasui $Y$, Shimozono $Y$, Kennedy JG. Surgical Procedures for Chronic Lateral Ankle Instability. J Am Acad Orthop Surg 2018;26(7):223-30. Crossref

14. Broström L. Sprained ankles: VI. Surgical treatment of "chronic" ligament ruptures. Acta Chir Scand 1966;132(5):551-65.

15. Gould N, Seligson D, Gassman J. Early and late repair of lateral ligament of the ankle. Foot Ankle 1980;1(2):84-9. Crossref

16. Lee KT, Lee JI, Sung KS, Kim JY, Kim ES, Lee SH, Wang JH. Biomechanical evaluation against calcaneofibular ligament repair in the Broström procedure: a cadaveric study. Knee Surg Sports Traumatol Arthrosc 2008;16(8):781-6. Crossref

17. Bell SJ, Mologne TS, Sitler DF, Cox JS. Twenty-six-year results after Broström procedure for chronic lateral ankle instability. Am J Sports Med 2006;34(6):975-8. Crossref

18. Tourné Y, Mabit C, Moroney PJ, Chaussard C, Saragaglia D. Long-term follow-up of lateral reconstruction with extensor retinaculum flap for chronic ankle instability. Foot Ankle Int 2012;33(12):1079-86. Crossref

19. Li X, Killie H, Guerrero P, Busconi BD. Anatomical reconstruction for chronic lateral ankle instability in the highdemand athlete: functional outcomes after the modified Broström repair using suture anchors. Am J Sports Med 2009;37(3):488-94. Crossref

20. Regauer M, Mackay G, Lange M, Kammerlander C, Böcker W. Syndesmotic InternalBrace (TM) for anatomic distal tibiofibular ligament augmentation. World J Orthop 2017;8(4):301-9. Crossref

21. Viens NA, Wijdicks CA, Campbell KJ, Laprade RF, Clanton TO. Anterior talofibular ligament ruptures: Part 1. Biomechanical comparison of augmented Broström repair techniques with the intact anterior talofibular ligament. Am J Sports Med 2014;42(2):405-11. Crossref

22. Willegger M, Benca E, Hirtler L, Hradecky K, Holinka J, Windhager R, Schuh R. Biomechanical stability of tape augmentation for anterior talofibular ligament (ATFL) repair compared to the native ATFL. Knee Surg Sports Traumatol Arthrosc 2016;24(4):1015-21. Crossref
23. Schuh R, Benca E, Willegger M, Hirtler L, Zandieh S Holinka $\mathrm{J}$, Windhager R. Comparison of Broström technique, suture anchor repair, and tape augmentation for reconstruction of the anterior talofibular ligament. Knee Surg Sports Traumatol Arthrosc 2016;24(4):1101-7. Crossref

24. Cho BK, Park KJ, Kim SW, Lee HJ, Choi SM. Minimal Invasive Suture-Tape Augmentation for Chronic Ankle Instability. Foot Ankle Int 2015;36(11):1330-8. Crossref

25. Coetzee JC, Ellington JK, Ronan JA, Stone RM. Functional Results of Open Broström Ankle Ligament Repair Augmented With a Suture Tape. Foot Ankle Int 2018;39(3):304-10. Crossref

26. Sanchez G, Ferrari MB, Sanchez A, Moatshe G, Chahla J, DePhillipo N, Provencher MT. Proximal Patellar Tendon Repair: Internal Brace Technique With Unicortical Buttons and Suture Tape. Arthrosc Tech 2017;6(2):e491-7. Crossref

27. Lubowitz JH, MacKay G, Gilmer B. Knee medial collateral ligament and posteromedial corner anatomic repair with internal bracing. Arthrosc Tech 2014;3(4):e505-8. Crossref

28. Mackay GM, Blyth MJ, Anthony I, Hopper GP, Ribbans WJ. A review of ligament augmentation with the InternalBrace ${ }^{\mathrm{TM}}$ : the surgical principle is described for the lateral ankle ligament and $A C L$ repair in particular, and a comprehensive review of other surgical applications and techniques is presented. Surg Technol Int 2015;26:239-55.

29. Giza E, Whitlow SR, Williams BT, Acevedo JI, Mangone PG, Haytmanek CT, Curry EE, Turnbull TL, LaPrade RF, Wijdicks CA, Clanton TO. Biomechanical Analysis of an Arthroscopic Broström Ankle Ligament Repair and a Suture AnchorAugmented Repair. Foot Ankle Int 2015;36(7):836-41. Crossref

30. Yoo JS, Yang EA. Clinical results of an arthroscopic modified Broström operation with and without an internal brace. J Orthop Traumatol 2016;17(4):353-60. https://doi. org/10.1007/s10195-016-0406-y

31. Vega J, Golanó P, Pellegrino A, Rabat E, Peña F. All-inside arthroscopic lateral collateral ligament repair for ankle instability with a knotless suture anchor technique. Foot Ankle Int 2013;34(12):1701-9. Crossref

32. Cottom JM, Rigby RB. The "all inside" arthroscopic Broström procedure: a prospective study of 40 consecutive patients. J Foot Ankle Surg 2013;52(5):568-74. Crossref

33. Lui TH. Modified arthroscopic Broström procedure. Foot Ankle Surg 2015;21(3):216-9. Crossref

34. Acevedo JI, Mangone PG. Arthroscopic lateral ankle ligament reconstruction. Tech Foot Ankle Surg 2011;10(3):111-116. Crossref

35. Corte-Real NM, Moreira RM. Arthroscopic repair of chronic lateral ankle instability. Foot Ankle Int 2009;30(3):213-7. Crossref

36. Kim ES, Lee KT, Park JS, Lee YK. Arthroscopic anterior talofibular ligament repair for chronic ankle instability with a suture anchor technique. Orthopedics 2011;34(4). Crossref

37. Vuurberg G, de Vries JS, Krips R, Blankevoort L, Fievez AWFM, van Dijk CN. Arthroscopic Capsular Shrinkage for Treatment of Chronic Lateral Ankle Instability. Foot Ankle Int 2017;38(10):1078-84. Crossref

38. Drakos M, Behrens SB, Mulcahey MK, Paller D, Hoffman E, DiGiovanni CW. Proximity of arthroscopic ankle stabilization procedures to surrounding structures: an anatomic study. Arthroscopy 2013;29(6):1089-94. Crossref

39. Acevedo JI, Ortiz C, Golano P, Nery C. ArthroBroström Lateral Ankle Stabilization Technique: An Anatomic Study. Am J Sports Med 2015;43(10):2564-71. Crossref 
40. Acevedo JI, Mangone P. Ankle instability and arthroscopic lateral ligament repair. Foot Ankle Clin 2015;20(1):59-69. Crossref

41. Song B, Li C, Chen N, Chen Z, Zhang Y, Zhou Y, Li W. All-arthroscopic anatomical reconstruction of anterior talofibular ligament using semitendinosus autografts. Int Orthop 2017;41(5):975-82. Crossref

42. Matsui K, Burgesson B, Takao M, Stone J, Guillo S, Glazebrook M; ESSKA AFAS Ankle Instability Group. Minimally invasive surgical treatment for chronic ankle instability: a systematic review. Knee Surg Sports Traumatol Arthrosc 2016;24(4):1040-8. Crossref

43. Kerkhoffs GM, Kennedy JG, Calder JD, Karlsson J. There is no simple lateral ankle sprain. Knee Surg Sports Traumatol Arthrosc 2016;24(4):941-3. Crossref

44. Messer TM, Cummins CA, Ahn J, Kelikian AS. Outcome of the modified Broström procedure for chronic lateral ankle instability using suture anchors. Foot Ankle Int 2000;21(12):996-1003.

45. Pagenstert GI, Hintermann B, Knupp M. Operative management of chronic ankle instability: plantaris graft. Foot Ankle Clin 2006;11(3):567-83. Crossref

46. Järvelä $T$, Weitz $H$, Järvelä $K$, Alavaikko $A$. A novel reconstruction technique for chronic lateral ankle instability: comparison to primary repair. Int Orthop 2002;26(5):314-7. Crossref

47. Boyer DS, Younger AS. Anatomic reconstruction of the lateral ligament complex of the ankle using a gracilis autograft. Foot Ankle Clin 2006;11(3):585-95. Crossref

48. Coughlin MJ, Schenck RC Jr, Grebing BR, Treme G. Comprehensive reconstruction of the lateral ankle for chronic instability using a free gracilis graft. Foot Ankle Int 2004;25(4):231-41. Crossref

49. Kim HN, Jeon JY, Dong Q, Noh KC, Chung KJ, Kim HK, Hwang $\mathrm{JH}$, Park $\mathrm{WW}$. Lateral ankle ligament reconstruction using the anterior half of the peroneus longus tendon. Knee Surg Sports Traumatol Arthrosc $2015 ; 23(6): 1877-85$. Crossref

50. Park CH, Lee WC. Donor Site Morbidity After Lateral Ankle Ligament Reconstruction Using the Anterior Half of the Peroneus Longus Tendon Autograft. Am J Sports Med 2017;45(4):922-8. Crossref

51. Sun $Y$, Wang $H$, Tang $Y$, Zhao $H$, Qin $S$, Zhang $F$. Reconstruction of the lateral ankle ligaments using the anterior half of peroneus longus tendon graft. Foot Ankle Surg 2017 pii: S1268-7731(17)31346-2. Crossref

52. Vuurberg G, Pereira H, Blankevoort L, van Dijk CN. Anatomic stabilization techniques provide superior results in terms of functional outcome in patients suffering from chronic ankle instability compared to non-anatomic techniques. Knee Surg Sports Traumatol Arthrosc 2017 [Epub ahead of print]. Crossref
53. Krips $R$, van Dijk CN, Halasi $T$, Lehtonen $H$, Moyen $B$, Lanzetta A, Farkas T, Karlsson J. Anatomical reconstruction versus tenodesis for the treatment of chronic anterolateral instability of the ankle joint: a 2- to 10-year follow-up, multicenter study. Knee Surg Sports Traumatol Arthrosc 2000;8(3):173-9. Crossref

54. Hsu AR, Ardoin GT, Davis WH, Anderson RB. Intermediate and Long-Term Outcomes of the Modified Broström-Evans Procedure for Lateral Ankle Ligament Reconstruction. Foot Ankle Spec 2016;9(2):131-9. Crossref

55. Taga I, Shino K, Inoue M, Nakata K, Maeda A. Articular cartilage lesions in ankles with lateral ligament injury. An arthroscopic study. Am J Sports Med 1993;21(1):126-7. Crossref

56. DiGiovanni BF, Fraga CJ, Cohen BE, Shereff MJ. Associated injuries found in chronic lateral ankle instability. Foot Ankle Int 2000;21(10):809-15. Crossref

57. Hintermann B, Boss A, Schafer D. Arthroscopic findings inpatients with chronic ankle instability. Am J Sports Med 2002;30(3):402-9. Crossref

58. Choi WJ, Lee JW, Han SH, Kim BS, Lee SK. Chronic lateral ankle instability: the effect of intra-articular lesionson clinical outcome. Am J Sports Med 2008;36(11):2167-72. Crossref

59. White WJ, McCollum GA, Calder JD. Return to sport following acute lateral ligament repair of the ankle in professional athletes. Knee Surg Sports Traumatol Arthrosc 2016;24(4):1124-9. Crossref

60. Benazzo F, Zanon G, Marullo M, Rossi SM. Lateral ankle instability in high-demand athletes: reconstruction with fibular periosteal flap. Int Orthop 2013;37(9):1839-44. Crossref

61. Kerkhoffs GM, Van Dijk CN. Acute lateral ankle ligament ruptures in theathlete: the role of surgery. Foot Ankle Clin 2013;18(2):215-8. Crossref

62. van den Bekerom MP, Kerkhoffs GM, McCollum GA, Calder JD, van Dijk CN. Management of acute lateral ankle ligament injury in the athlete. Knee Surg Sports Traumatol Arthrosc 2013;21(6):1390-5. Crossref

63. Shawen SB, Dworak T, Anderson RB. Return to Play Following Ankle Sprain and Lateral Ligament Reconstruction. Clin Sports Med 2016;35(4):697-709. Crossref

64. Nery C, Raduan F, Del Buono A, Asaumi ID, Cohen M, Maffulli N. Arthroscopic-assisted Broström-Gould for chronic ankle instability: a long-term follow-up. Am J Sports Med 2011;39(11):2381-8. Crossref

65. Arroyo-Hernández $M$, Mellado-Romero $M$, Páramo-Díaz $P$, García-Lamas L, Vilà-Rico J. Chronic ankle instability: Arthroscopic anatomical repair. Rev Esp Cir Ortop Traumatol 2017;61(2):104-10. Crossref 